\title{
Memory for concrete and abstract words in bilingual speakers
}

\author{
EUGENE WINOGRAD \\ Emory University, Atlanta, Georgia 90322 \\ CAROLYN COHEN \\ Indiana University, Bloomington, Indiana 47401 \\ and \\ JOHN BARRESI \\ Dalhousie University, Halifax, Nova Scotia, Canada
}

\begin{abstract}
The dual-code hypothesis of Paivio was taken to imply that bilingual speakers should show poorer memory for the language in which concrete words appeared than the language in which abstract words appeared. The results of two experiments with German-English bilinguals, one using a recognition memory procedure and the other using the free recall task, found the opposite state of affairs. Semantic recognition, free recall, and memory for language of occurrence were all found to be superior for concrete words. Two hypotheses were advanced. One, called the "cultural imagery hypothesis," assumes that images may be culture specific, while the other hypothesis interprets the outcome in terms of the relations between stored attributes. An analysis of the experiment as an attribute-memory procedure is presented.
\end{abstract}

The purpose of the research reported here was to pursue some hypotheses about how concrete and abstract words are stored by utilizing the special properties of bilingual speakers. The major reason for investigating word concreteness is that rated word concreteness or imagery has been shown to have powerful effects on memory in a variety of tasks (see Paivio, 1971, for a review). Concrete words are easier to recall and recognize than abstract words (Paivio, in press). Why should this be so? Paivio and his associates have made a strong case for the argument that, for concrete words, both verbal and imaginal codes are stored in memory and that the additional image code is the source of the observed mnemonic superiority. According to Paivio, the essential property of images is that they are nonverbal and their essential mnemonic function lies in providing an additional code which serves as the basis of improved performance.

We now must briefly consider bilingualism and how it relates to these concerns. In the literature on memory in bilinguals, it is common to see the major theoretical issue stated in terms of a dichotomy between the language-independent storage hypothesis and the

Experiment I was part of a Senior Honor's Thesis completed by the second author under the direction of the first author at Emory University. We are grateful to James McMahon for his advice on the problems of translation. This research was supported by National Science Foundation Grant GB-18703 to the first author. Reprint requests should be sent to Eugene Winograd, Department of Psychology, Emory University, Atlanta, Georgia 30322. language-dependent storage hypothesis (e.g., Liepmann \& Saegert, 1974). The language-independent storage hypothesis says that bilingual speakers treat words in terms of their meanings and represent them in a supralinguistic code which is independent of the language in which the word occurred. Appended to this hypothesis is the corollary that information about language may be attached to the semantic code as a sort of footnote, so that language information is potentially retrievable. The language-dependent storage hypothesis seems to maintain that there are essentially separate languagespecific storage systems. Without undertaking a literature review here, it is safe to say that there is enough evidence against a pure language-dependent storage hypothesis to allow us to undertake the present investigation, whose basic theoretical concern may be put as the question: Is there greater language independence for concrete than for abstract words?

The experimental question of primary concern in our research is about memory for the language code. If abstract material is represented primarily in a verbal code, then subjects should have greater success in remembering in which language such words were studied, German or English. To look at it from the other direction, if concrete words are partly represented in a nonverbal image code, then to the extent that subjects rely on this code at retrieval, information about language of occurrence should be poorer for concrete than for abstract words. Of course, if all studied words, both concrete and abstract, are represented in some abstract propositional code (Anderson \& Bower, 1973; Pylyshyn, 
1973) of whose nature we have very little idea, then no difference might be expected in remembering the language of occurrence. We will reserve discussion of what the remaining alternative, i.e., better language recognition of concrete words, might suggest for later on. Two experiments are reported, the first primarily concerned with recognition memory and the second with free recall. In both experiments, data on memory for language were obtained.

\section{EXPERIMENT I}

The first experiment, comprising two related studies, employed a combined recognition memory and attribute memory procedure similar methodologically to procedures reported by Kintsch (1970) and by Kolers and Ostry (1974). After studying a mixed list of concrete and abstract words in German and English, subjects were presented with a test list on which some of the studied words appeared in the same language as at study and others in translation. Subjects were asked to indicate for each word one of three choices: "Same," if they thought that the test word had been seen before in the same form; "Other," for words now appearing in translation; or "Neither," indicating that the concept shown had not been studied in either language. Kintsch (1970) has shown that German-English bilinguals are capable of remembering the language in which a concept occurred at levels well above chance but not without error. In the present case, we ask whether such memory for language differs for concrete and abstract words.

\section{Method}

Subjects. Seventeen German-English bilingual adults were recruited from the Emory and Atlanta communities and were paid for their participation. There were eight subjects in Group 1 and nine subjects in Group 2. Eight subjects considered English to be their dominant language, seven subjects chose German, and two subjects said that neither language was dominant. On a 7 point scale of fluency, self-ratings averaged 6.5 for the stronger language and 5.6 for the weaker, with four subjects assigning equal ratings to both languages. A criterion for participation was that at least 1 year had been spent living in a country where the second language was predominantly used. The average number of years spent in such an environment was 7.6. All subjects could converse with ease in either language.

Materials. The same study list of 96 nouns was used for both groups in Experiment 1. It consisted of a randomization of four groups of 24 words each. The four 24-word groups were made up of the four possible combinations of language, English or German and concreteness, high or low. Because of the ready availability of English language norms of rated imagery and word frequency, the lists were constructed in English, with subsequent translation to German. All translations were reviewed by a professor of German whose native language is English. His rejections were based on a personal criterion of equivalence. Cognates were excluded from the list. The mean rated concreteness (Paivio, Yuille, \& Madigan, 1968) for the 48 concrete words was 6.79 ; for the 48 abstract words, the mean rating was 2.59 . All words were of high English word frequency. For Group 1, an additional 14 concrete and 14 abstract words were chosen in similar fashion to serve as distractors on the recognition test. The words used are presented in the Appendix.
In composing the list, it seemed to our language consultant that the interlanguage equivalence was greater for the concrete words. This is an interesting point and, if true, itself bears upon the dual-code hypothesis. Some support for this observation comes from a study of Kolers (1963) which found that word associations given across languages were more similar to withinlanguage associations for concrete than for abstract words. Unfortunately, a small pool of words was used in Kolers' study. To the extent that translations of concrete words have greater semantic overlap than do translations of abstract words, memory for language of concrete words should be more difficult.

On the test sheet, for both groups, half of the old words were printed in the same language as at study and the other half of the words appeared in the other language, i.e., in translation. There were eight test categories for the old words: concrete words presented in English at study and tested in English (same or EE); concrete words presented in German and tested in German (same or GG); concrete words presented in English and tested in German (other or EG); concrete words presented in German and tested in English (other or GE); plus the same four conditions for abstract words. There were two test forms for each group to counterbalance the words tested in the same language (EE and GG) and those tested in the other language (EG and GE).

Groups 1 and 2 differed only in that, in addition to the old words, the test sheet for Group 1 contained an additional 28 nouns which were new, i.e., they had not been studied in either language. These distractors were also subdivided into four groups of concrete English, concrete German, abstract English, and abstract German. For Group 2, there were no distractor items presented at all.

Procedure. All study words were printed individually on index cards in lowercase letters, with the first letter of German words capitalized, and presented to each subject separately at a $5-\mathrm{sec}$ rate. The words were shown in a random order, with the constraint that no more than two words in the same language could appeax consecutively. Subjects were told that the experiment was about memory for words and that the list would contain words in both English and German. They were told to try to remember the words, but nothing was said about concreteness, memory for language, or the nature of the test. The typed recognition test sheet was handed to the subject as soon as the last of the 96 words had been shown. Subjects in Group 1 were asked to respond by writing " $S$ " for same next to the word if it was an old word appearing in the same language as at study, "O" for other if it had the same meaning as a studied word but was in the other language, or " $N$ " for neither if the test word had not appeared in either language. Subjects in Group 2 were given a test sheet which contained none of the 28 distractors. They were told that they had seen all of the 96 words earlier in one of the two languages and were to write either " $S$ " for $E E$ and GG words or "O" for EG and GE words.

Analysis. For Group 1, the data analysis followed the same approach taken by Kolers and Ostry (1974). While their interest was in memory for the typography in which a sentence had appeared and ours is for the language in which a word appeared, the problems of measurement are much the same. Performance was looked at in three different ways. One measure, called $d^{\prime}($ sem) by Kolers and Ostry, concerns semantic recognition and assesses the recognition of concepts without requiring correct language identification. For $\mathrm{d}^{\prime}(\mathrm{sem})$ both same (EE and GG) and other (GE and EG) test items were taken as old items; likewise, responses of either "same" or "other" to such items are hits, or recognition of an old concept whether or not language identification was correct. The false alarm rate was the proportion of appropriate distractor items (concrete or abstract) assigned to same or other (old) categories. By this analysis, the threecategory judgment allowed the subject is reduced to the twocategory (old or new) judgment customary in recognition memory work. The second measure, called $\mathrm{d}^{\prime}(\mathrm{new})$ by Kolers 
and Ostry, defines hits more stringently in that language recognition is required. For EE and GG items, only responses of "same" were counted as hits; the corresponding false alarm rate was the proportion of appropriate new items called "same." For EG and GE items, only responses of "other" counted as hits, while false alarms were appropriate new items called "other."

The measure of special interest is what Kolers and Ostry called $d^{\prime}($ old $)$. This measure here assesses language recognition, given that semantic recognition has occurred; that is, it looks at assignment to language for only those old concepts to which the subject has said "same" or "other." For EE and GG items, for example, hits are computed as the number of such items called "same" divided by the total number of such items called "same" and "other." The corresponding false alarm rate is the number of "same" responses to EG and GE items divided by the total number of these items called "same" or "other." The vaiue of $d^{\prime \prime}($ old $)$ is the same whether computed for same items (EE and $G G$ ) or for other (EG and GE) items. In analyses using $\mathrm{d}^{\prime}$ scores, which were computed for each subject, hit rates of 1.0 and false alarm rates of zero were treated as .98 and .02 , respectively, before converting to $d^{\prime}$ values from the tables found in Swets (1964).

\section{Results}

The mean response proportions upon which all the reported analyses are based are shown in Table 1 . As no systematic or significant differences were found between German and English, the data are combined across languages. Kintsch (1970) also found no language difference in recognition memory for German-English bilinguals. It can be seen from Table 1 that, for old concepts classified as old (the entries for Group 1 in the first four rows and the first two columns), language identification, as Kintsch (1970) found, is considerably above chance but not perfect. The language-dependent storage hypothesis receives little support from this pattern. In what follows, the two major groupings of the data are by word concreteness and by same vs. other language testing, with major emphasis given to concreteness. Statistical analyses were performed on both corrected recognition scores, the conventional score obtained by subtracting the appropriate false alarm proportion from the proportion of hits, and on the corresponding $\mathrm{d}^{\prime}$ scores.

The data for Group 1 appear in Tables 24. Table 2 shows the proportions of hits, false alarms, corrected recognitions, and scores for semantic recognition, or $\mathrm{d}^{\prime}(\mathrm{sem})$. Both "same" and "other" responses to old concepts were counted as hits in these calculations. For the corrected recognition scores, a two-way ANOVA with both Concreteness and Same vs. Other Language at Test as within-subject factors yields Concreteness as the only significant variable, $\mathrm{F}(1,7)=10.18, \mathrm{MS}_{\mathrm{e}}=$ $.030, p<.05$. For $d^{\prime}$, none of the outcomes are significant; for concreteness, $\mathrm{F}(1,7)=5.40, \mathrm{MS}_{\mathrm{e}}=.406$, $p<.10$. The difference between semantic recognition of concrete and abstract words is almost entirely attributable to a false alarm rate for abstract words (.32), which is twice as great as for concrete words (.16), a finding recently noted by Morris and Reid (1974) in a unilingual
Table 1

Mean Response Proportions

\begin{tabular}{lllll}
\hline & & \multicolumn{3}{c}{ Response } \\
\cline { 3 - 5 } \multicolumn{1}{c}{ Group 1 } & & & & \\
Cord & "Same" & "Other" "Neither" \\
Same Language & Concrete & .69 & .08 & .23 \\
(EE and GG) & Abstract & .52 & .17 & .30 \\
Other Language & Concrete & .12 & .58 & .30 \\
(EG and GE) & Abstract & .16 & .53 & .30 \\
New & Concrete & .06 & .10 & .84 \\
\multicolumn{1}{c}{ Group 2 } & & .14 & .18 & .68 \\
Same Language & Concrete & .83 & .17 & \\
(EE and GG) & Abstract & .74 & .26 & \\
Other Language & Concrete & .09 & .91 & \\
(EG and GE) & Abstract & .26 & .74 \\
\hline
\end{tabular}

Table 2

Mean Semantic Recognition Proportions and Mean d'(sem): Group 1

\begin{tabular}{|c|c|c|c|c|c|}
\hline & Words & Hits & $\begin{array}{c}\text { False } \\
\text { Alarms }\end{array}$ & $\begin{array}{c}\text { Corrected } \\
\text { Recogni- } \\
\text { tions }\end{array}$ & $\mathrm{d}^{\prime}$ \\
\hline $\begin{array}{l}\text { Same Language } \\
\text { (EE and GG) }\end{array}$ & $\begin{array}{l}\text { Concrete } \\
\text { Abstract }\end{array}$ & $\begin{array}{l}.77 \\
.70\end{array}$ & $\begin{array}{l}.16 \\
.32\end{array}$ & $\begin{array}{l}.61 \\
.38\end{array}$ & $\begin{array}{l}1.91 \\
1.24\end{array}$ \\
\hline $\begin{array}{l}\text { Other Language } \\
\text { (EG and GE) }\end{array}$ & $\begin{array}{l}\text { Concrete } \\
\text { Abstract }\end{array}$ & $\begin{array}{l}.70 \\
.70\end{array}$ & $\begin{array}{l}.16 \\
.32\end{array}$ & $\begin{array}{l}.54 \\
.38\end{array}$ & $\begin{array}{l}1.62 \\
1.25\end{array}$ \\
\hline
\end{tabular}

Table 3

Mean Language Recognition Proportions and Mean d'(new): Group 1

\begin{tabular}{|c|c|c|c|c|c|}
\hline & Words & Hits & $\begin{array}{c}\text { False } \\
\text { Alarms }\end{array}$ & $\begin{array}{l}\text { Corrected } \\
\text { Recogni- } \\
\text { tions }\end{array}$ & $d^{\prime}$ \\
\hline $\begin{array}{l}\text { Same Language } \\
\text { (EE and GG) }\end{array}$ & $\begin{array}{l}\text { Concrete } \\
\text { Abstract }\end{array}$ & $\begin{array}{l}.69 \\
.52\end{array}$ & $\begin{array}{l}.06 \\
.14\end{array}$ & $\begin{array}{l}.63 \\
.38\end{array}$ & $\begin{array}{l}2.09 \\
1.63\end{array}$ \\
\hline $\begin{array}{l}\text { Other Language } \\
\text { (EG and GE) }\end{array}$ & $\begin{array}{l}\text { Concrete } \\
\text { Abstract }\end{array}$ & $\begin{array}{l}.58 \\
.53\end{array}$ & $\begin{array}{l}.10 \\
.18\end{array}$ & $\begin{array}{l}.48 \\
.35\end{array}$ & $\begin{array}{l}1.63 \\
1.25\end{array}$ \\
\hline
\end{tabular}

recognition memory study comparing concrete and abstract words.

When the data of Table 1 are treated as described above (see Analysis) for language recognition, or $\mathrm{d}^{\prime}$ (new), with hits now requiring correct language recognition, the data for Group 1 appear as shown in Table 3. The effect of word concreteness is significant for both corrected recognitions, $\mathrm{F}(1,7)=25.88, \mathrm{MS}_{\mathrm{e}}=$ .010 , and for $\mathrm{d}^{\prime}, \mathrm{F}(1,7)=22.34, \mathrm{MS}_{\mathrm{e}}=.134, \mathrm{p}<.01$ in each case.

The comparison of greatest interest is for language identification of those concrete and abstract words which have been semantically recognized, the $d^{\prime}($ old $)$ measure as defined above. For Group 1, we are looking only at those items which subjects have identified as being semantically familiar, and are asking how well 
Table 4

Mean Language Recognition Proportions Conditional on Semantic Recognition and Mean d'(old): Group 1

\begin{tabular}{ccccc}
\hline Words & Hits & $\begin{array}{c}\text { False } \\
\text { Alarms }\end{array}$ & $\begin{array}{c}\text { Corrected } \\
\text { Recognitions }\end{array}$ & $\mathrm{d}^{\text {(n) }}$ \\
\hline Concrete & .90 & .15 & .74 & 2.52 \\
Abstract & .77 & .25 & .52 & 1.54 \\
\hline
\end{tabular}

Table 5

Mean Language Recognition Proportions and Mean d: Group 2

\begin{tabular}{ccccc}
\hline Words & Hits & $\begin{array}{c}\text { False } \\
\text { Alarms }\end{array}$ & $\begin{array}{c}\text { Corrected } \\
\text { Recognitions }\end{array}$ & $\mathrm{d}^{\prime}$ \\
\hline Concrete & .83 & .09 & .74 & 2.29 \\
Abstract & .74 & .26 & .48 & 1.26 \\
\hline
\end{tabular}

these items are remembered with respect to language. As Table 1 shows, subjects did occasionally say "same" to an item which was actually studied in the other language and "other" to an item which was identical in form to a studied item. The results of this conditional analysis are shown in Table 4 for Group 1. Performance is better in all cases for the concrete words. For the corrected recognition measure, $t(7)=3.73$, and for $\mathrm{d}^{\prime}, \mathrm{t}(7)=4.88$; in both cases $\mathrm{p}<.01$.

Table 5 presents the data for Group 2. It will be recalled that this group was not shown any distractor items at test and could respond only with "same" or "other." Therefore, all test items enter into this analysis. The observed superiority for concrete words is significant for both corrected recognitions and $\mathrm{d}^{\prime}$ by sign test, $\mathrm{p}<.01$, with all nine subjects gaining higher scores for the concrete words.

This experiment, then, yields a consistent pattern, with performance found to be better for concrete words on all measures. When only semantically recognized concepts are examined, subjects are more likely to remember the language in which a concrete word occurred than an abstract word. This outcome does not appear to follow from the dual-code hypothesis as described in the introduction. It should also be noted that there is no evidence from any of the recognition measures of facilitation due to showing a test word in the same language in which it was studied: A translated repetition is equivalent to an identical repetition. It would be premature to take this as evidence against a visual feature match or pattern analysis for the following reason. It is a real possibility that our subjects were attempting to meet the task demands of the experiment by considering every test word in both its presented form and in translation before reaching a same-other decision. Such a strategy could act to mask an effect of testing in the same language. Before further discussion of these results, we report a second experiment.

\section{EXPERIMENT II}

In Experiment II we approached the question of differential storage of concrete and abstract words with the free recall task. It has been shown by several investigators (e.g., Glanzer \& Duarte, 1971; Kolers, 1966; Lambert, Ignatow, \& Krauthamer, 1968) that a translated repetition increases the probability of recall of a semantic unit to the same extent as an identical repetition when recall from long-term memory is assessed. In none of these studies, however, has the concrete-abstract dimension been explored. It is possible that predominantly concrete words were used in these studies. With concrete words, a common image code across languages may be the basis of the reported equivalence of identical and translated repetitions for recall. If only a verbal code is relied on with abstract items, repetition in translation may not facilitate recall as much for these items as for concrete words. In this experiment, then, an explicit recall comparison was made between concrete and abstract words of the effects of repetition in the same and other language. A possible interaction of Type of Repetition by Concreteness was, therefore, of interest here. In addition, language recognition was tested after recall was completed.

\section{Method}

Subjects. The subjects were 13 German-English bilinguals. German was the native language for 10 subjects and English for the other 3. Five subjects regarded German as their dominant language, four chose English, and four said both or neither. Although a criterion of having spent at least 1 year in an environment where the second language was spoken was used in both studies, one subject in Experiment II actually spent only 6.5 months in such a setting. This person was included since he considered himself to be equally fluent in both languages. On the 7-point fluency scale, the mean rating assigned to each language was identical at 6.92. The sample of subjects in this study differs from the sample of Experiment $I$ in containing fewer people associated with academic life.

Materials. Nine lists of 20 items each were composed from the words used in Experiment I, with each list containing 12 semantic types. On each list there were four semantic types which were not repeated and eight which were repeated, giving 20 tokens. Of the four nonrepeated types, two were concrete and two abstract, one of each kind occurring in German and the other in English. Of the eight repeated types, four were concrete and four abstract, with half of each kind repeated in the same language (EE and GG items) and the other half repeated in the other language (EG and GE items). With $A$ representing abstract and $C$ representing concrete, each of the nine lists studied by each subject may be represented as follows: $C G, C E, A G, A E$, CGG, CEE, AGG, AEE, CGE, CEG, AGE, AEE. For example, CGG indicates a concrete type which appeared twice in German, while AGE represents an abstract type which appeared once in German and once in English. A sample list follows: Zeit (AGG), cradle (CEG), Tier (CGG), Eitelkeit (AG), gratitude (AEG), Zeit (AGG), apple (CE), Schnur (CGE), cooperation (AEE), Tier (CGG) Entschuldigung (AGE), Wiege (CEG), caterpillar (CEE), Dankbarkeit (AEG), cooperation (AEE), Schaum (CG), string (CGE), caterpillar (CEE), justice (AE), excuse (AGE). 
The 20 tokens on each of the nine lists were presented in a random order, with the restriction that repetitions had to be separated by at least five items. This spacing rule was adopted because of Glanzer and Duarte's (1971) finding that, at spacings of five items, identical and translated repetitions facilitated recall to the same extent for Spanish-English bilinguals.

Procedure. Questions about language background were asked at the beginning of the session and instructions were then read. Subjects were told about the bilingual nature of the lists but, as in Experiment I, not about the concrete-abstract dichotomy. They were told that some, but not all, words would be repeated and that some of the repetitions would be in translation. The instructions emphasized that repeated words should only be written once during the recall phase and that this applied to words repeated in the other language as well as to identical repetitions. Practice was given in counting backward by threes before the first list was presented. All words were shown on index cards at a $3-\mathrm{sec}$ rate. Three seconds after the last word on each list was shown, a card bearing a three-digit number was shown to which subjects were asked to count backward by threes, in either language, at his or her own pace until told to stop. Twenty seconds were allowed for this, followed immediately by written recall. A language recognition test was administered following recall on the ninth list. Each of the 108 semantic types appeared on the test sheets paired in both languages. The instructions written on the top of the test sheet were: "Circle one or both of the following words in each pair if they appeared during the study session. Do not skip any pairs-at least one of the words occurred during study." The instructions were amplified by the experimenter where needed. The purpose of this test was to enable us to compare memory for language for those concrete and abstract words which had been recalled earlier.

\section{Results}

Recall. Mean recall proportions (of 18 words) over the nine study lists are shown in Table 6 . Analysis of variance for the repeated items confirms what the proportions indicate: Word concreteness alone yields a significant effect, $F(1,12)=7.28, M_{e}=6.339, p<.05$. The important interaction of Concreteness by Type of Repetition gives an $\mathrm{F}$ of less than unity. These results confirm the bilingual equivalence effect found by others and indicate that it holds for both abstract and concrete words. Recall of both kinds of repeated words is, of course, significantly higher than recall of the nonrepeated words. The superiority in recall for concrete over abstract words is not significant for the nonrepeated words, $t(12)=.91$, although such a difference would be expected by the dual-code hypothesis. However, it should be noted that there were relatively few nonrepeated words on the lists.

Comparison between German and English words is possible for nonrepeated words and words repeated in the same language. The only comparison showing any indication of a language effect is the recall of abstract repeated words, where more German words (mean of 5.40 out of nine words) than English words (mean recall of 3.20 words) are recalled, $t(12)=3.64, p<.01$. Mean recall was the same (2.30 words) for both languages for nonrepeated abstract words, however, and there was no language effect for concrete words.

Three kinds of recall errors were tallied apart from the above analyses. Eleven of the 13 subjects gave a
Table 6

Mean Proportion of Words Recalled: Experiment II

\begin{tabular}{lccc}
\hline & Singles & $\begin{array}{c}\text { Repeated } \\
\text { Same } \\
\text { Language }\end{array}$ & $\begin{array}{c}\text { Repeated } \\
\text { Other } \\
\text { Language }\end{array}$ \\
\hline Concrete & .30 & .59 & .58 \\
Abstract & .26 & .48 & .49 \\
\hline
\end{tabular}

total of 24 prior list intrusions, that is, wrote down on the recall test for the current list words which had occurred on lists studied earlier. Of these 24 intrusions, 12 were concrete and 12 abstract; 21 were repeated words and 3 were singles. Seven subjects gave a total of 17 decipherable intrusions which had not appeared in any lists; 10 of these were concrete and 7 abstract. The third type of error was recalling in the wrong language a word which had occurred in only one language (E, G, EE, and GG words), e.g., recalling "time" when only "zeit" had appeared, or vice versa. Unfortunately, there were only six instances of this theoretically interesting type of error, of which five were for concrete words. While such an outcome would be in line with expectations of greater reliance upon an image code with concrete words, the small number of errors of this type is an indication that the language attribute is indeed a "well-formed code," in Kolers' terms (1965), or, alternatively, that our subjects would not commit themselves on concepts of whose language code they were uncertain.

Language recognition of recalled items. In order to make the concrete and abstract words more comparable, only those items for the nine study lists which had been recalled were considered in this analysis. To review, following recall the subjects were presented with the paired German and English versions of all the concepts and were asked to circle only those forms which had been seen earlier. For recalled semantic types which had appeared in only one language (E, G, EE, and GG items), a recognition hit was defined as circling the correct and only the correct member of the pair; for types which had been repeated in translation (EG and GE pairs), a hit was defined as circling both members of the pair. Corresponding false alarms were, for E, G, EE, and GG items, the proportion of recalled EG and GE items in which only one word was circled and, for EG and GE items, the number of recalled EE and GG items in which both items were circled.

The conditional recognition data are shown in Table 7. The proportions for single items are based on a small number of recalled items (see Table 6), and the higher recognition scores for abstract words are not significant; for corrected recognitions, $t(12)=1.60$; for $d^{\prime}, t(12)=1.49$. For EE and GG words, language recognition is about the same for concrete and abstract words, but for EG and GE words, the superior language recognition of recalled concrete words is reliable: For corrected recognitions, $t(12)=2.62$; for $\mathrm{d}^{\prime}, \mathrm{t}(12)=2.70$, $\mathrm{p}<.05$ in each case. 
Table 7

Mean Recognition Scores for Recalled Words of Experiment II

\begin{tabular}{llcccc}
\hline & Words & Hits & FA & CR & $\mathrm{d}^{\prime}$ \\
\hline Singles & Concrete & .76 & .47 & $.35^{*}$ & 1.29 \\
(E and G) & Abstract & .87 & .40 & $.51^{*}$ & 1.94 \\
Repeated Same & Concrete & .90 & .47 & .43 & 1.59 \\
(EE and GG) & Abstract & .84 & .40 & $.47^{*}$ & 1.70 \\
Repeated Other & Concrete & .53 & .06 & .48 & 1.80 \\
(GE and EG) & Abstract & .42 & .14 & $.28^{*}$ & .97 \\
\hline
\end{tabular}

*Denotes some subjects whose negative $C R$ score was treated as .00.

\section{DISCUSSION}

The results may be summarized by the observation that performance was generally superior for concrete words. In Experiment I both semantic recognition and memory for language were better for concrete words; in Experiment II recall was better for concrete words, and memory for language for recalled words was either equivalent for concrete and abstract words or better for the concrete words. In addition, there was no indication in Experiment II of a recall interaction between word concreteness and whether repetition was in the same or other language.

What do these results tell us about the storage of concrete and abstract words? In terms of the hypotheses advanced earlier, it is tempting to conclude that the failure to find either better language identification conditional on semantic recognition for abstract words in Experiment I or a recall interaction in Experiment II suggests that there is no qualitative difference in the way in which the two kinds of words are stored. Such a conclusion, however, would be premature for at least two reasons. In the first place, we have reproduced the common finding of superior recall and recognition for concrete words and extended it to the bilingual setting. This mnemonic superiority of concrete words remains the strongest arguing point for proponents of different codes associated with the two types of material.

Second, there are some ways in which our findings can be encompassed by a revision of dual-code theory. One such account we call the "cultural imagery hypothesis." Besides assuming that images are more likely to be evoked by concrete than abstract words, this hypothesis suggests that, for bilinguals who have lived in different milieus corresponding to their two different tongues, memory images are likely to carry information about cultural context and, thereby, language (see Lambert, Havelka, \& Crosby, 1958, for a similar argument). The image associated with "Hund" is not the same as the image associated with "dog;" while meanings may be generic, images are specific. In short, the "cultural imagery hypothesis" proposes that the image provides information from which the language of occurrence may be decoded.
A less speculative line of reasoning goes as follows. Assume that lexical events are coded as a collection of features among which are separate ones containing information about images and language. For reasons we do not understand, image or visual features may be especially effective cues for retrieving information about other features stored at the same time. Successful recognition of concrete words will often be achieved via recovery of the image feature, which, in turn, has a high probability of leading to successful retrieval of other encoded features such as the language in which the concept in question occurred. Hence, the better memory found for the language attribute with concrete words. Light, Berger, and Bardales (1975) have recently reported some findings which lend support to this argument. In their experiment, subjects studied words of high and low rated imagery which appeared in different typecases and colors. A combined recognition memory and attribute memory test followed, as in our Experiment I. Both semantic recognition and memory for the visual attributes, conditionalized on semantic recognition, were superior for the high-imagery words, in agreement with the results found here.

Both the present findings and those of Light et al. support the hypothesis that, whatever feature it is that differentiates concrete from abstract words (which we have called the "image" attribute) may, in addition to facilitating semantic recognition and recall, also facilitate the retrieval of other contextual elements once it has been recovered itself. In any case, the finding that word imagery contributes to memory for language of input suggests that the verbal and image codes may not be independent. Further research into attribute memory with words varying in rated imagery may prove useful toward gaining an understanding of how concrete and abstract words are represented in memory.

\section{APPENDIX}

\section{Concrete Study Words}

Tier-animal, Arzt-doctor, Gebäude-building, Brett-board, Leib-body, Meer-sea, Gewitter-storm, Schnur-string, Koniginqueen, Puppe-doll, Pfeil-arrow, Schmetterling-butterfly, Heerarmy, Vogel-bird, Krankenhaus-hospital, Eisen-iron, Richterjudge, Staub-dust, Fahne-flag, Bild-picture, Fenster-window, Turm-tower, Pfirsich-peach, Uberschwemmung-flood, caterpillar-Raupe, boy-Junge, tree-Baum, table-Tisch, railroadEisenbahn, forest-Wald, furniture-Möbel, circle-Kreis, skinHaut, ankle-Fussknöchel, cradle-Wiege, toy-Spielzeng, cattleVieh, corner-Ecke, girl-Mädchen, potato-Kartoffel, prisonGefängnis, coin-Münze, village-Dorf, valley-Tal, mule-Maultier, snake-Schlange, restaurant-Gaststätte, fork-Gabel.

\footnotetext{
Abstract Study Words

Wissenschaft-science, Mehrheit-majority, Leben-life, Erlaubnis-permission, Zeit-time, Tugend-virtue, Starke-strength, Betrag-amount, Fahigkeit-ability, Entdeckung-discovery, Kenntnis-knowledge, Wahrheit-truth, Forschung-research, Sehvermogen-vision, Pflicht-duty, Entschuldigung-excuse, Tatsache-fact, Sieg-victory, Schweigen-silence, Zufall-chance, Hass-hatred, Scherz-joke, Hoffnung-hope, Augenblick-moment,
} 
custom-Gewohnheit, freedom-Freiheit, safety-Sicherheit, expression-Ausdruck, confidence-Vertraven, advantage-Vorteil, crime-Verbrechen, fate-Schicksal, development-Entwicklung, justice-Gerechtigkeit, memory-Gedächtnis, law-Gesetz, necessityNotwendigkeit, opinion-Meinung, poetry-Dichtkunst, honorEhre, gratitude-Dankbarkeit, glory-Ruhm, pleasure-Vergnügen, pride-Stolz, direction-Richtung, quality-Eigenschaft, legislationGesetzgebung, event-Ereignis.

\section{Concrete Distractors}

Jelly, barrel-Fass, sulphur, dove-Taube, tablespoon-Esslüffel, forehead-Stirn, apple-Apfel, Nagel-nail, Tür-door, Schaum-foam, Bargeld, Pantoffel-slipper, Bleistift-pencil, Metzger-butcher.

\section{Abstract Distractors}

Advice, anxiety-Angst, cooperation-Mitwirkung, editionAusgabe, explanation-Erklärung, folly, misery-Elend, Segen, Verstand, Eitelkeit-vanity, Jahreszeit-season, Verlobungengagement, Gedeihen-prosperity, Vergleich-comparison.

\section{REFERENCES}

ANDERSON, J. R., \& Bower, G. H. Human associative memory. Washington, D.C: Winston, 1973.

Glanzer, M.. \& Duarte, A. Repetition between and within languages in free recall. Journal of Verbal Learning and Verbal Behavior, 1971, 10, 625-630.

Kintsch, W. Recognition memory in bilingual subjects. Journal of Verbal Learning and Verbal Behavior, 1970, 9, 405-409.

Kolers. P. A. Interlingual word associations. Joumal of Verbal Learning and Verbal Behavior. 1963, 2, 291-300.

Kolers, P. A. Bilingualism and bicodalism. Language and Speech. 1965, 8, 122-126.

Kolers. P. A. Interlingual facilitation of short-term memory. Journal of Verbal Lecrning and Verbal Behavior, 1966, 5. 314-319.
Kolers, P. A..\& Ostry, D. J. Time course of loss of information regarding pattern analyzing operations. Journal of Verbal Learning and Verbal Behavior, 1974, 13, 599-612.

Lambert, W. E., Havelka, J.. \& Crosby, C. The influence of language-acquisition contexts on bilingualism. Journal of Abnormal and Social Psychology, 1958. 56. 239-244.

Lambert, W. E.. Ignatow, M.. \& Krauthamer. M. Bilingual organization in free recall. Journal of Verbal Learning and Verbal Behavior, 1968, 7, 207-214.

LIEPMANN, D. \& SAEGERT, J. Language tagging in bilingual free recall. Joumal of Experimental Psychology, 1974. 103. 1137-1141.

Light, L. L., Berger, D. E., \& Bardales, M. Trade-off between memory for verbal items and their visual attributes. Journal of Experimental Psychology: Human Learning and Memory, 1975, 104, 188-193.

MORRIS. F. E.. \& REID, R. L. Imagery and recognition. British Journal of Psychology, 1974, 65, 7-12.

PaIvio. A. Imagery and verbal processes. New York: Holt. Rinehart, \& Winston, 1971.

PAIvio, A. Imagery in recall and recognition. In J. Brown (Ed.), Recall and recognition. New York: Wiley, in press.

Paivio, A., Yullle, J. C., \& Madigan, S. Concreteness. imagery, and meaningfulness values for 925 nouns. Journal of Experimental Psychology Monograph Supplement. 1968. 76. (No. 1, Part 2), 1-25.

Pylyshy, $Z$. W. What the mind's eye tells the mind's brain: A critique of mental imagery. Psychological Bulletin. 1973 , 80, 1-24.

SwETs. J. A. (Eds.). Signal detection and recognition by human observers. New York: Wiley. 1964.

(Received for publication July 7, 1975; revision accepted October 27, 1975.) 